\title{
Novel hydrothermal solution routes of advanced high melting nanomaterials processing
}

\author{
K. BYRAPPA ${ }^{\dagger}$ \\ University of Mysore, Post Box No. 21, DOS in Earth Sciences, Manasagangotri, Mysore 570 006, India
}

\begin{abstract}
Novel hydrothermal solution processing routes covering conventional hydrothermal, solvothermal and supercritical hydrothermal techniques are becoming the most efficient routes for advanced nanomaterials processing including the high melting compounds. The importance of these novel hydrothermal solution routes has been discussed with appropriate examples. The current trends in the hydrothermal solution processing of materials, the importance of solubility study, thermodynamic calculations and the role of surfactants and chelates have been discussed in detail. The multi-energy processing of materials, instant hydrothermal system and the new concept in materials processing, viz. Chemistry at the speed of light have been highlighted here. The hydrothermal synthesis of nanomaterials of carbon polymorphs, rare earth vanadates, metal oxides and their nanocomposites have been discussed with an emphasis on the control of size and morphology.
\end{abstract}

(C2009 The Ceramic Society of Japan. All rights reserved.

Key-words : Novel hydrothermal solution routes, Hydrothermal, Solvothermal, Supercritical hydrothermal, Nanoparticles processing, Carbon polymorphs, Titania nanoparticles, Zinc oxide nanoparticles, Rare earth vanadates nanoparticles, Nanocomposites

[Received December 15, 2008]

\section{Introduction}

The term advanced material is referred to a chemical substance whether organic or inorganic or mixed in composition possessing desired physical and chemical properties. In the current context the term materials processing is used in a very broad sense to cover all sets of technologies and processes for a wide range of industrial sectors. Obviously, it refers to the preparation of materials with a desired application potential. There are several methods of processing advanced materials like physical vapour deposition, colloidal chemistry approach, mechanical milling, mechanical alloying techniques, sol-gel, mechanical grinding, hydrothermal, biomimitic, flame pyrolysis, laser ablation, ultrasound techniques, electrodeposition process, plasma synthesis techniques, microwave techniques, other precipitation processes, etc. Among these processes, the hydrothermal technique contributes to only around $6 \%$. However, it has been realized that the hydrothermal technique facilitates the fabrication of even the toughest or the most complex material(s) with a desired physico-chemical properties. Novel hydrothermal solution routes is a recent concept to describe a set of processes in a broader sense covering conventional hydrothermal (with aqueous solvent in the system), solvothermal (with non-aqueous solvent in the system) and supercritical hydrothermal (either aqueous or nonaqueous under supercritical conditions) processes. The term hydrothermal is purely of geological origin. It was first used by the British geologist Sir Roderick Murchison (1792-1871) to describe the action of water at elevated temperature and pressure, in bringing about changes in the earth's crust leading to the formation of various rocks and minerals. It is well known that the largest single crystal formed in nature (beryl crystal of $>1000 \mathrm{~kg}$ ) and some of the largest quantity of single crystals created by man in one experimental run (quartz crystals of several 1000s kg) are both of hydrothermal origin. ${ }^{1)}$ Hydrothermal processing can be

Corresponding author: K. Byrappa; E-mail: kbyrappa@gmail.com defined as any homogeneous (nanoparticles) or heterogeneous (bulk materials) reaction in the presence of aqueous solvents or mineralizers under high pressure and temperature conditions to dissolve and recrystallize (recover) materials that are relatively insoluble under ordinary conditions. Byrappa and Yoshimura (2001) define hydrothermal as any homogeneous or heterogeneous chemical reaction in the presence of a solvent (whether aqueous or non-aqueous) above the room temperature and at pressure greater than $1 \mathrm{~atm}$ in a closed system. ${ }^{2}$ Here the authors have defined the term hydrothermal in a traditional and broader sense covering conventional hydrothermal, solvothermal and supercritical hydrothermal processes.

Among various technologies available today in advanced materials processing, the hydrothermal technique occupies a unique place owing to its advantages over conventional technologies. It covers processes like hydrothermal synthesis, hydrothermal crystal growth leading to the preparation of fine to ultra-fine and nano crystals, bulk single crystals, hydrothermal transformation, hydrothermal sintering, hydrothermal decomposition, hydrothermal stabilization of structures, hydrothermal dehydration, hydrothermal extraction, hydrothermal treatment, hydrothermal phase equilibria, hydrothermal electrochemical reactions, hydrothermal recycling, hydrothermal microwave supported reactions, hydrothermal-mechanochemical, hydrothermal sonochemical, hydrothermal electrochemical processes, hydrothermal fabrication, hot pressing, hydrothermal metal reduction, hydrothermal leaching, hydrothermal corrosion, and so on. The hydrothermal processing of advanced materials has lots of advantages and can be use to give high product purity and homogeneity, crystal symmetry, metastable compounds with unique properties, narrow particle size distributions, a lower sintering temperature, a wide range of chemical compositions, single-step processes, dense sintered powders, submicron to nano-particles with a narrow size distribution using simple equipment, lower energy requirements, fast reaction times, lowest residence time, as well as for the growth of crystals with polymorphic modifica- 
tions, the growth of crystals with low to ultra low solubility, and a host of other applications. Since then the knowledge on the physical chemistry, PVT relationship in the hydrothermal systems greatly improved, which helped in drastically reducing the temperature and pressure conditions of processing. Similarly the solvothermal and supercritical processing which used a variety of other solvents like organic, organometallic complexes in materials processing, thereby taking this technology towards Green Chemistry.

\section{Current trends in hydrothermal solution processing}

The hydrothermal solution processing of materials on the whole has undergone a myriad evolution since its inception as a tool to process technological materials in the sense; the PT conditions of processing are now inclined towards the green technology. Table 1 gives the trends in hydrothermal processing of materials, and takes hydrothermal technology towards green technology for sustained human development since it consumes less energy, no or little solid waste/or waste liquid/gases, no recover treatment, no hazardous process materials, high selectivity, closed system of processing, etc. ${ }^{3)}$ The important subjects of technology in the 21 st century are predicted to be the balance of environmental and resource and or energy problems. This has led to the development of a new concept related to the processing of advanced materials in the 21 st century, viz., industrial ecology or the science of sustainability. ${ }^{4}$ Hydrothermal chemistry has to be understood precisely in order to process the materials under soft and environmentally benign conditions. The behaviour of the solvent under hydrothermal conditions dealing with aspects like structure at critical, supercritical, and sub-critical conditions, dielectric constant, $\mathrm{pH}$ variation, viscosity, coefficient of expansion, density, etc. are to be understood with respect to pressure and temperature. Today much of the hydrothermal research is done based on the intelligent modelling of the hydrothermal reactions prior to the actual experiments. This greatly helps in predicting the experimental conditions to obtain a desired phase with a controlled shape and size. ${ }^{5,6)}$ The modeling is based on the thermodynamic principles and today there are several commercially available software for thermodynamic calculations. One can precisely predict the experimental conditions and also construct the yield diagrams for a given system. Figure 1 shows the yield diagram for the hydroxyapatite system. ${ }^{7)}$ Such a rational approach has been used quite successfully to predict optimal synthesis conditions for controlling phase purity, particle size, size distribution, and particle morphology of PZT and other systems.

More recently, the addition of external energy like microwave energy, sonar, or mechanochemical, electrical, magnetic, etc. into

Table 1. Current Trends in Hydrothermal Technology $y^{3)}$

\begin{tabular}{lll}
\hline \multicolumn{1}{c}{ Compound } & \multicolumn{1}{c}{ Earlier Work } & \multicolumn{1}{c}{ Author* } \\
\hline $\mathrm{Li}_{2} \mathrm{~B}_{4} \mathrm{O}_{7}$ & $T=500-700^{\circ} \mathrm{C}$ & $T=240^{\circ} \mathrm{C}$ \\
& $P=500-1500$ bars & $P=<100$ bars \\
$\mathrm{Li}_{3} \mathrm{~B}_{5} \mathrm{O}_{8}(\mathrm{OH})_{2}$ & $T=450^{\circ} \mathrm{C}$ & $T=240^{\circ} \mathrm{C}$ \\
& $P=1000$ bars & $P=80$ bars \\
& $T=700-900^{\circ} \mathrm{C}$ & $T=200^{\circ} \mathrm{C}$ \\
$\mathrm{NaR}\left(\mathrm{WO}_{4}\right)_{2}$ & $P=2000-3000$ bars & $P=<100$ bars \\
$\mathrm{R}=\mathrm{La}, \mathrm{Ce}, \mathrm{Nd}$ & Melting Point & $T=100^{\circ} \mathrm{C}$ \\
$\mathrm{R}: \mathrm{MVO}_{4}$ & $>1800^{\circ} \mathrm{C}$ & $P=<30$ bars \\
$\mathrm{R}=\mathrm{Nd}, \mathrm{Eu}, \mathrm{Tm} ; \mathrm{M}=\mathrm{Y}, \mathrm{Gd}$ & $T<120^{\circ} \mathrm{C}$ \\
$\mathrm{LaPO}_{4}$ & Synthesized at & $P<40$ bars \\
& $>1200^{\circ} \mathrm{C}$ &
\end{tabular}

hydrothermal has opened up a new chapter in materials processing. It is being popularly referred to as multi-energy processing of materials. ${ }^{8}$ This takes the hydrothermal technology to a new and totally unexplored avenue in the 21 st century. The duration of experiments is reduced by at least 4 orders of magnitude which in turn make the technique more economic. It not only enhances the reaction kinetics in materials crystallization, but it evolves a new concept like chemistry at the speed of light. This has also led to the other concepts called Instant Hydrothermal System, and Automatic Hydrothermal Vending Machine to synthesize particles instantly. ${ }^{9)}$ This future concept of a Materials Scientist is shown in Fig. 2.

The hydrothermal technique has a special significance in the processing of advanced nanomaterials. The solution techniques like hydrothermal is becoming the most valuable nanomaterials fabrication tool in the recent years, and it has an edge over all other processing methods because of the high quality of products. By choosing the appropriate capping agents, surface properties of the nanoparticles can be significantly altered from hydrophilic to hydrophobic and vice versa. Also a perfect disper-

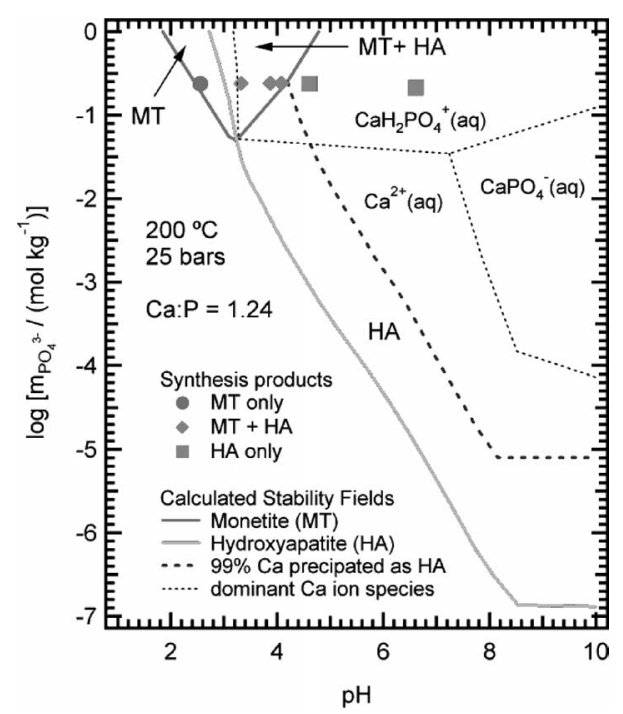

Fig. 1. Calculated stability field diagram for the HAp system at $200^{\circ} \mathrm{C}$ and 25 bars with $\mathrm{Ca}: \mathrm{P}$ ratio at $1.24 .^{7)}$

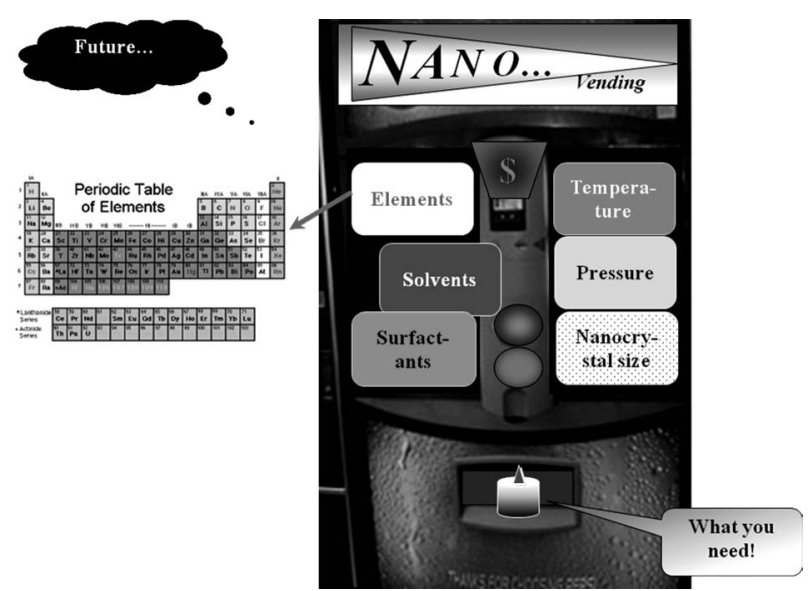

Fig. 2. Materials scientists concept of future nanovending machine to obtain desired nanomaterials instantly. 
sion of the nanoparticles in the given solvent can be achieved for making the self assembly structures. The knowledge on the nucleation, crystallization, self-assembly, and the growth mechanism of the nanocrystals in hydrothermal solution media are rather complicated and are still not well understood.

Gold nanoparticles have been around since Roman times. As per the literature data, Michael Faraday was the first to seriously experiment with gold nanoparticles starting in the $1850 \mathrm{~s} .{ }^{10)}$ The development of new sophisticated tools like STM, TEM, AFM, etc. to observe, measure and manipulate processes at the nanoscale level gave a breakthrough to the nanotechnology. Majority of the early hydrothermal experiments carried out during 1840s to early 1900 s mainly dealt with the nanocrystalline products, which were discarded as failures due to the lack of sophisticated tools to examine the fine to nano-products except some chemical techniques. ${ }^{11-14)}$ Until the works of Giorgio Spezia in 1900, the hydrothermal technology did not gain much importance in the growth of bulk crystals, as the products in majority of the cases were very fine grained and sub-microscopic in size without any X-ray data. ${ }^{15)}$ But today, it has evolved as one of the most efficient methods of soft chemistry in processing the advanced materials like nanomaterials with a controlled size, shape and physical characteristics. The in situ fabrication of the materials is the present trend in materials processing without involving postsynthesis treatment. This is the greatest advantage of hydrothermal processing, which facilitates the in situ size, morphology control, and also surface modification. In solution processing the key parameter is the solvent. In case of hydrothermal processing the solvent plays multiple roles and its role has to be understood clearly in order to work out a mechanism for materials processing under hydrothermal conditions.

The supercritical hydrothermal method is an extension of hydrothermal technology. The distinct difference between the conventional hydrothermal and supercritical hydrothermal technology in the present day context is that hydrothermal is treated as more closer to the soft solution processing or mild technique, ${ }^{16), 17)}$ whereas the supercritical hydrothermal technology deals with the reactions at temperatures just near or above the critical temperature. The supercritical hydrothermal has witnessed a seminal growth in its application to the processing of a variety of materials owing to the availability of a wide range of solvents. The supercritical hydrothermal method with water as a solvent is highly suitable for the nanoparticle fabrication of a wide range of high melting ionorganic compounds and also for hybrid organic-inorganic hybrid nanoparticles. There are several variants in the supercritical fluid technology like static supercritical fluid process (SSF), rapid expansion of supercritical solutions (RESS), particles from gas-saturated solutions (PGSS), gas antisolvent process (GAS), precipitation from compressed antisolvent (PCA), aerosol solvent extraction system (ASES), supercritical antisolvent process (SAS), solution enhanced dispersion by supercritical fluids (SEDS), supercritical antisolvent process with enhanced mass transfer (SAS-EM), depressurization of an expanded liquid organic solution (DELOS), supercritical assisted atomization (SAA), hydrothermal synthesis under supercritical conditions via flow reactor (HTSSF), hydrothermal synthesis under supercritical conditions via batch reactor (HTSSB), supercritical fluids drying (SCFD), supercritical fluid extraction emulsions (SFEE), etc. ${ }^{18)}$

Depending upon the action, the application and the apparatus are selected for hydrothermal processing of materials. The most commonly used apparatus in hydrothermal solution processing are the simple General Purpose autoclaves, Stirred reactors,
Batch reactors, Flow reactors, etc. The designing and fabrication of apparatus related to the hydrothermal technique with multienergy applications like hydrothermal with microwave, or sonar, or mechanical, magnetic, and also for the waste-free processing of materials is still an attractive area of research.

\section{Solubility}

The solubility and the distribution of ionic species in solution are also important for the understanding of hydrothermal reaction atmosphere. These two parameters can be predicted by calculating $\mathrm{K}$ for each reaction, mass balance and charge balance. There are several models available today to estimate the solubility of the species of interest based on the dissociation reaction in a given system. Even by using the value estimated from the ionic radius reported in the literature, the solubility behaviour trend can be precisely estimated. It is well known that the experimental results could be well correlated with various models to express the increase of solubility with increasing temperature (for positive solubility materials) and increase of solubility with decrease of temperature (for negative solubility materials), and the dramatic decrease of solubility around the critical point. ${ }^{19)}$ That is the greatest advantage of supercritical hydrothermal conditions unlike the conventional hydrothermal or solvothermal conditions.

\section{Surface modification}

The important step in the processing of fine particles of advanced materials is the use of surfactants and chelates to control the nucleation of a desired phase, such that the phase homogeneity, size, shape and dispersibility could be achieved during the crystallization of the fine particles. This marked the beginning of the study of precursor preparation for different systems, the surface interactions with the capping agents or surfactants, and polymerized complexes. The surfaces of the particles could be altered to hydrophobic or hydrophilic depending upon the applications. ${ }^{20), 21)}$ Today this approach is playing a key role in nanotechnology to prepare highly dispersed, oriented and self assembled particles. Figure 3 shows the new preparative chemical approach for the precursors preparation. Such an approach leads to the processing of highly controlled and also selfassembled particles of even complex and multi-component materials. Using such an approach a wide range of advanced materials like lead zirconium titanate (PZT) family of ceramics, ferrites, phosphates, sulphides, oxides, hydroxyapatites, etc., and com-

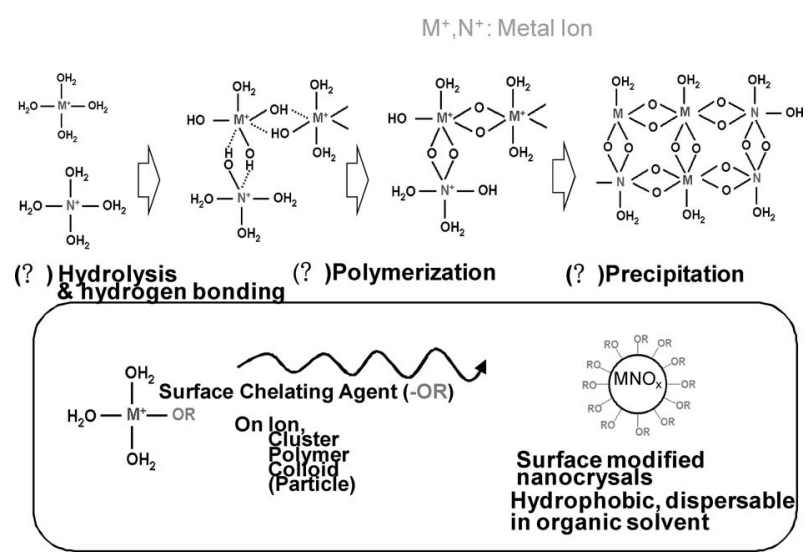

Fig. 3. Modifiers and chelating agents used in the preparation of fine particles. 
posites have been prepared as fine particles for technological applications with preferred morphology such as whiskers, rods, needles, plates, spheres, etc. depending upon the applications. This precursor based chemical approach to hydrothermal synthesis has made a tremendous progress in recent years and also drastically reduced the temperature and pressure conditions of processing of materials. The addition of surface modifiers also helps to inhibit the crystal growth that facilitates the smaller particles size with a narrow particle size distribution. Figure 4 shows the TEM images of nanoparticles synthesized under supercritical hydrothermal conditions. As is clearly seen from Fig. 4, those nanoparticles without modifier are aggregated and they do not disperse in the aqueous solvents. Also the particle size is larger compared to the modified particles. When the $p H$ of the reaction medium is highly acidic or highly basic, very small particles along with the large particles are formed leading to a broader size distribution. It seems that because of redissolv-

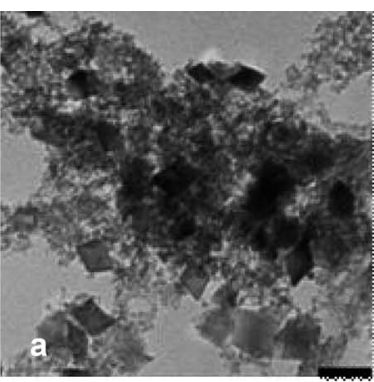

50

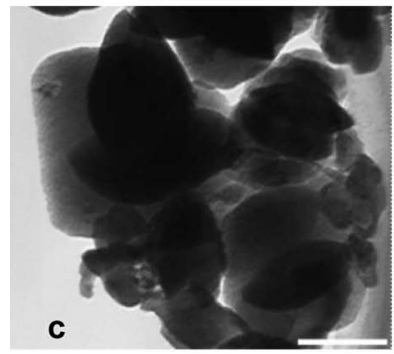

100
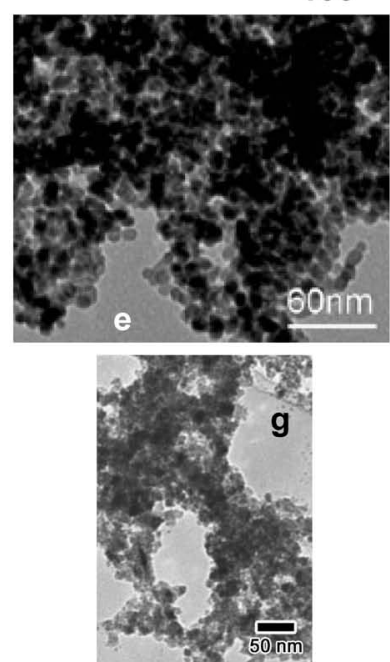

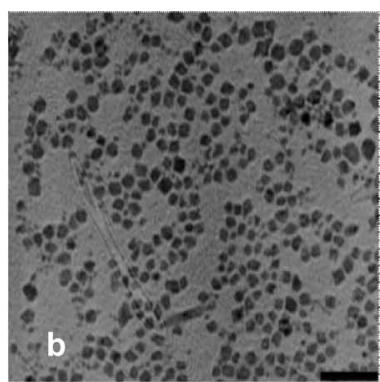

50

nms.

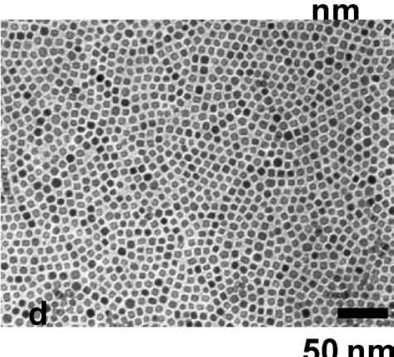

$50 \mathrm{~nm}$
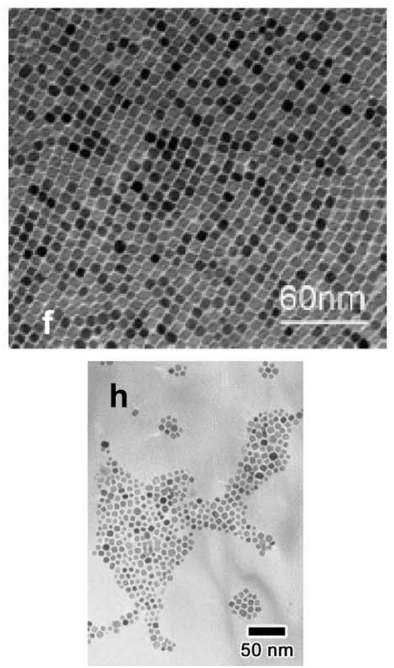

Fig. 4. TEM images of nanoparticles synthesized under supercritical hydrothermal conditions: a) $\mathrm{Fe}_{2} \mathrm{O}_{3}$ (without modifier), b) $\mathrm{Fe}_{2} \mathrm{O}_{3}$ (with modifier), c) $\mathrm{Co}_{3} \mathrm{O}_{4}$ (without modifier), d) $\mathrm{Co}_{3} \mathrm{O}_{4}$ (with modifier), e) $\mathrm{CeO}_{2}$ (without modifier), f) $\mathrm{CeO}_{2}$ (with modifier), g) $\mathrm{TiO}_{2}$ (without modifier), h) $\mathrm{TiO}_{2}$ (with modifier). ${ }^{22)}$ ing of nanoparticles at very high and low $p H$, Ostwald repining occurs. Therefore, in surface modification, $p H$ of the medium, isolectric point (iep) and another important parameter, viz. dissociation constant $(p K a)$ of the modifiers are very important. At $p H$ below $p K a$, the modifier does not dissociate. Moreover, below iep, the surface of metal oxide nanoparticles is surrounded by positive charges (major) and hydroxylic groups (minor). Under these conditions there is no chemical reaction occurring between the modifier and the metal oxide nanoparticle surface, but it is only through a strong hydrogen bonding the modifier can attach to the nanoparticles surface. In contrary, at higher $p H$ than $p K a$, dissociation of modifier takes place and results in chemical reaction between dissociated part of modifier and $\mathrm{OH}_{2}{ }^{+}$from particles surface. Thus, by dehydration reaction modifier attaches to the surface of the particles. By considering the chemical reactions, mass balances, charge balance in the actual system, $p H$ and the modifier can be fixed for most of the systems.

\section{Hydrothermal solution processing of selected advanced high melting nanomaterials}

The nanomaterials are known for their unique mechanical, chemical, physical, thermal, electrical, optical, magnetic and also specific surface area properties, which in turn define them as nanostructures, nanoelectronics, nanophotonics, nanobiotechnology, nanoanalytics, etc. In the last one decade a large variety of nanomaterials and devices with new capabilities have been generated employing nanoparticles based on metals, metal oxides, ceramics (both oxide and non-oxide), silicates, organics, polymers, etc. One of the most important properties of materials in nano size regime is the changing physical properties. nanoparticles possess unique optical and electronic properties not observed for corresponding bulk samples. A major challenge in the nanomaterials science is the accurate control of the size and shape, which in turn is directly linked with the nanomaterials processing method. Nanoparticles can be obtained from a great variety of processes involving the conversion of solid to solid or liquid to solid or gas to solid. The stringent requirements for the biological applications like the therapeutic, bioimaging, hyperthermia, targeted drug delivery system, biosensors, MRI, microelectronics, etc. insist on the control of the size and shape of nanomaterials. Hence, the solution techniques like hydrothermal is becoming the most valuable nanomaterials fabrication tool in the recent years, and it has an edge over all other processing methods because of the high quality of products. ${ }^{18)}$ By choosing the appropriate capping agents, surface properties of the nanoparticles can be significantly altered from hydrophilic to hydrophobic and vice versa. Also a perfect dispersion of the nanoparticles in the given solvent can be achieved for making the self assembly structures. The knowledge on the nucleation, crystallization, self-assembly, and the growth mechanism of the nanocrystals in hydrothermal solution media are rather complicated and are still not well understood.

In this review, the authors describes the hydrothermal solution processing of high melting compounds like carbon polymorphs, titania, zinc oxide, rare earth vanadates and coating of metal oxides on the calcium alumina-silicate beads having application potential in various technological fields. The apparatus used in these experiments include General Purpose autoclaves, Batch Reactors, Tuttle-Roy type reactors, Flow reactors and Stirred reactors. The experiments were carried out using Teflon liners and platinum liners depending upon the experimental conditions. The experimental temperature varied from 100 to $800^{\circ} \mathrm{C}$ and pressure varied from a few bars to 2.5 kbars. A wide range of 
solvents were used in all the experiments covering both aqueous and non-aqueous solvents.

\subsection{Hydrothermal solution processing of carbon polymorphs}

The synthesis of different carbon polymorphs such as graphite, diamond, amorphous carbon or diamond-like carbon, fullerenes, carbon nanotubes, etc., has attracted considerable interest for a long time because of their importance in science and technology. Attempts to synthesize these forms with varied conditions and techniques, sometimes even violating the thermodynamic principles, have met with a fair amount of success. The stabilities of graphite and diamond in nature were mainly controlled by $\mathrm{P}-\mathrm{T}-\mathrm{fO}_{2}$ in the $\mathrm{C}-\mathrm{O}-\mathrm{H}$ system. ${ }^{23)-26)}$ The role of $\mathrm{C}-\mathrm{O}-\mathrm{H}$ fluids, ${ }^{27,28)}$ as well as the hydrothermal and organic origin ${ }^{29), 30)}$ of these polymorphs, especially with reference to diamond genesis, prompted the material scientists to explore the possibility of synthesizing them at fairly low pressure and temperature conditions. The hydrothermal technique is highly promising for reactions involving volatiles, as they attain the supercritical fluid state and supercritical fluids are known for their greater ability to dissolve non-volatile solids. ${ }^{31)}$ Our group has investigated the decomposition of silicon carbide and chromium carbide in the presence of an organic compound in the temperature range 300 to $800^{\circ} \mathrm{C}$ with pressure up to $200 \mathrm{MPa}$ and the experimental duration of 24 to $120 \mathrm{~h}$ using platinum capsules placed inside the Tuttle-Roy autoclaves. The experiments with silicon carbide and organics mainly showed quartz and volatiles as by-products and carbon phase as the main. The experiments with chromium carbide and organics yielded chromium oxide, volatiles and filamentous carbon. The Fig. 5 shows the SEM images of spherical, filamentous, ovoid shaped carbon particles and diamond particles. These particles have been obtained in the presence of organics like malic acid, glycolic acid, oxalic acid, malonic acid, stearic acid, ascorbic acid, citric acid, etc. ${ }^{32)-34)}$ Quantification of the mechanism leading to the formation of desired shape and type of carbon formation is difficult since the phenomenon observed as above is not unique to any of the particular conditions of formation. The Fig. 6 shows the laser Raman for the run product and the commercial graphite and diamond.
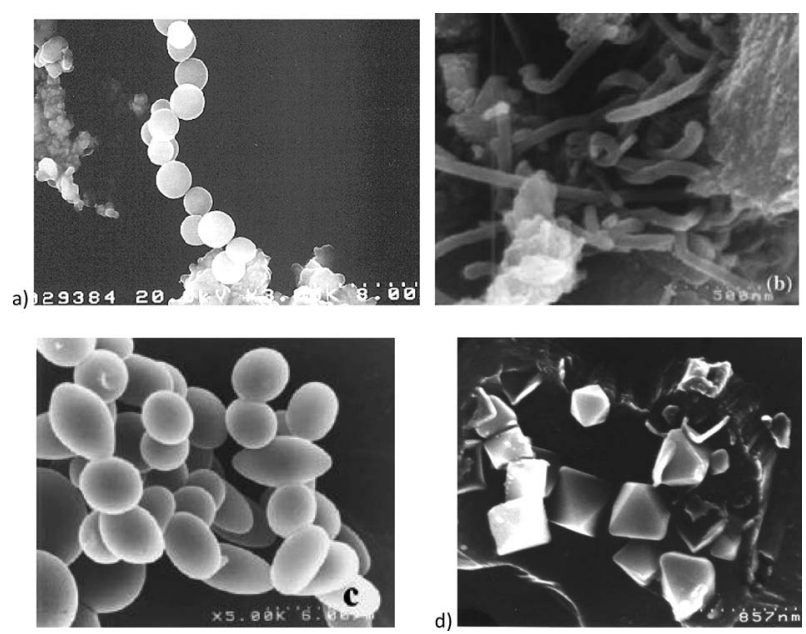

Fig. 5. SEM images of the carbon polymorphs: a) spherical particles, b) filamentous carbon, c) ovoid shape carbon particles, d) $s p^{3}$ bonded carbon (diamond) (from author's group).

\subsection{Rare earth vanadates}

$\mathrm{YVO}_{4}: \mathrm{R}^{3+}$ and $\mathrm{GdVO}_{4}: \mathrm{R}^{3+}$ (where $\mathrm{R}=\mathrm{Nd}, \mathrm{Er}, \mathrm{Eu}$ ) are known as efficient laser host materials, excellent polarizer, and as a phosphor in its powder form. ${ }^{35)}$ These compounds show high melting and no phase transitions. The synthesis of the rare earth vanadates is popular by the conventional methods like flux and melt techniques. The materials prepared by these conventional methods encountered several problems like oxygen vacancies resulting in major structural defects, presence of mixed phases in the products, and loss of vanadium during crystallization. In order to overcome these problems, the hydrothermal technique was proposed by Byrappa et al. ${ }^{36}$ ) Followed by this several reports appeared on the hydrothermal preparation of fine crystals and nanocrystals of these rare earth vanadates. ${ }^{18), 37), 38)}$ Both acidic and basic mineralizers are used in the synthesis as solvents in all the works. These solvents with yttrium and vanadium compounds yield only macro-size to nano-size crystals of rare earth vanadates. The addition of EDTA, or ammonium metavanadate, or surfactant like gluconic acid into the system stunt the growth of larger particles, and produce nanoparticles of rare earth vanadates. The synthesis has been carried out by the present author using hydrothermal method at sub-critical to supercritical temperatures 220 to $400^{\circ} \mathrm{C}$ (Fig. 7). The use of supercritical hydrothermal solution method with a residence time of 2.08 seconds has resulted in the formation of highly dispersed nanoparticles of $\mathrm{Eu}^{+3}: \mathrm{GdVO}_{4}$ with 10 to $15 \mathrm{~nm}$ size. The absence of $\mathrm{OH}-$ mole-

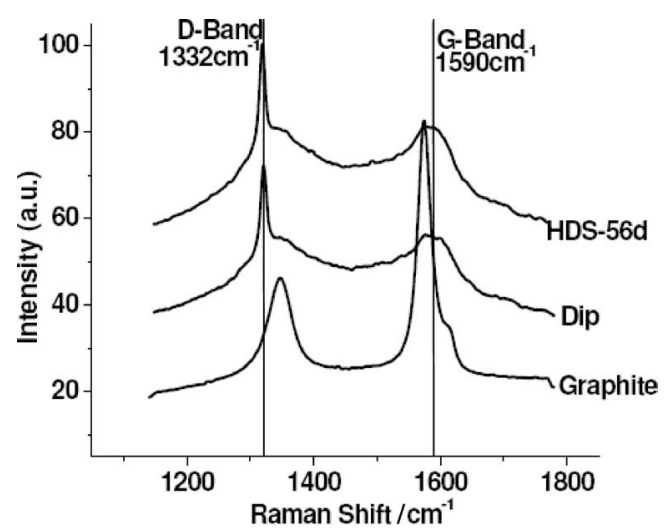

Fig. 6. Raman spectra of run product and commercial products (graphite and diamond).
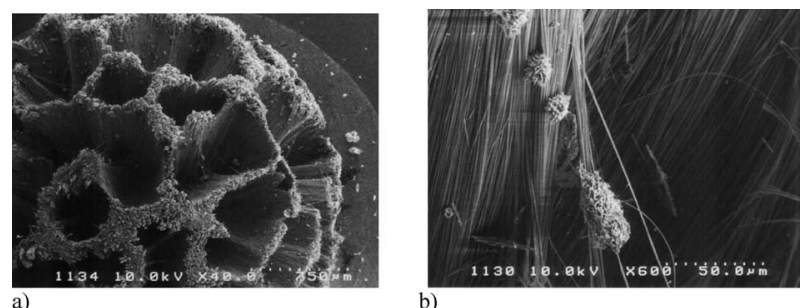

a)
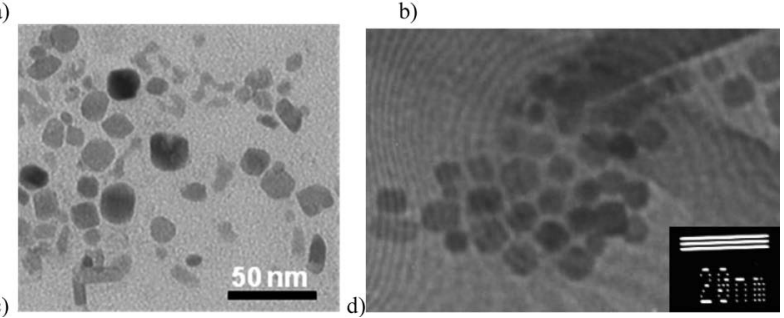

Fig. 7. Rare earth vanadates nanostructures (from the author's work). 
cules in the final products suggest that hydrothermal solution method could become the most versatile one for the processing of these rare earth vanadates for a variety of applications.

\subsection{Metal oxides}

Metal oxide nanoparticles have garnered a great deal of interest among researchers owing to their unique properties for applications not only in ceramics, coatings, catalysts, sensors, semiconductors, magnetic data storage, solar energy devices, ferrofluids, but also in medical field such as hyperthermia, bioimaging, cell labeling, special drug delivery systems, and so on. However, their application potential is dictated by their surface nature, particle size, and also shape. Although the synthesis of metal oxides is not new, their applications were limited. With the discovery of size quantization effect in these materials during 1980s, there is a seminal progress in the synthesis of these metal oxides with desired properties for several new applications. Among the metal oxides $\mathrm{TiO}_{2}$ and $\mathrm{ZnO}$ have a special place in the modern technology.

\subsubsection{Titania}

Titania is one of the most studied semiconductors for solar cells and photocatalytic reactions due to its low cost, ease of handling, and high resistance to photo-induced decomposition. ${ }^{39-41)}$ $\mathrm{TiO}_{2}$ shows maximum light scattering with virtually no absorption. It is non-toxic and chemically inert. It also has a special photocatalytic sterilization function, which can be used for antibacterial applications. ${ }^{42)}$ These unique properties of titania are directly related to the crystallinity, size, shape and dopants. Among all the methods hydrothermal and supercritical hydrothermal methods are the most popular preparative methods of titania nanoparticles. $\mathrm{TiO}_{2}$ (rutile or anatase) nanoparticles have been prepared popularly starting from stabilized $\mathrm{TiCl}_{4}$ solutions. Some researchers have used the combination of hydrolysis and polycondensation of titanium tetra-isopropoxide, $\mathrm{Ti}(\mathrm{OR})_{4}$ in the presence of tetramethyl ammonium hydroxide, with a preliminary heat treatment under reflux, and experimental temperature, $T=175-200^{\circ} \mathrm{C}$ over a period up to $5 \mathrm{~h}$. Usually the titania prepared in supercritical ethanol exhibit a higher degree of crystallinity and contain less hydroxide. The smaller particles have proved to be the best candidates for the photocatalytic applications owing to the larger surface area. However, the conventional hydrothermal methods yield larger particles and hence the supercritical hydrothermal is the most viable method for producing smaller particles with a shortest residence time. ${ }^{43)}$ Also the properties of titania particles could be easily enhanced through a systematic approach to the synthesis methods. There are several reports on the in-situ surface modification of the titania nanoparticles during the hydrothermal solution processing both under sub-critical and supercritical conditions. Adschiri et al. ${ }^{44)}$ have done such in-situ surface modification of $\mathrm{TiO}_{2}$ nanoparticles (Figs. 4(g), (h)) under supercritical hydrothermal conditions using hexaldehyde as a surfactant. Similarly, the present author has prepared tungsten doped titania nanoparticles under subcritical hydrothermal conditions $\left(T=240^{\circ} \mathrm{C} ; P=30\right.$ bars; experimental duration $=16 \mathrm{~h}$ ) using caprylic acid and n-butylamine as surfactants (Fig. 8). The binding of the organic molelcules used for surface modification might not be physical adsorption, but rather covalent binding. The titania particles without surfactant were aggregated with a broad size distribution, whereas those synthesized with surfactant were more dispersed and with a size range up to $10 \mathrm{~nm}$. The immobilization of the organic molecules immediately after the nucleation of the particles probably suppressed the growth nuclei, and in addition, the formation of the a)

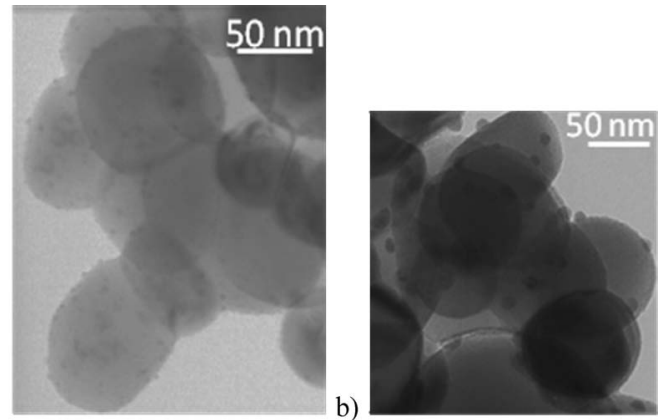

Fig. 8. Tungsten doped titania nanoparticles obtained under subcritical hydrothermal conditions using a) caprylic acid; b) $n$-butylamine surfactants (Present author's work).

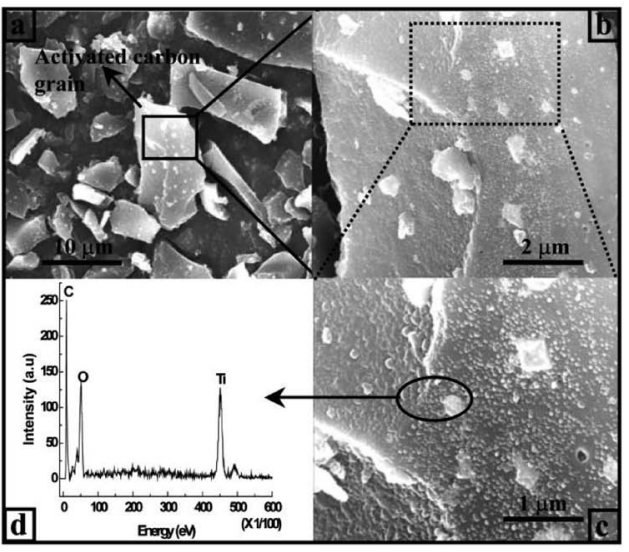

e)

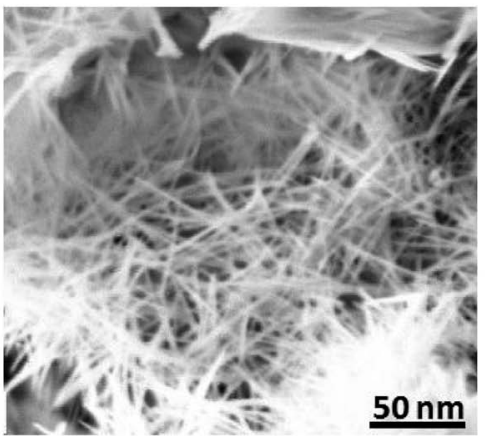

Fig. 9. Nanocomposites: a) $\mathrm{TiO}_{2}$ particles adhered onto activated carbon surface, b) A portion enlarged, c) Enlarged portion showing $\mathrm{TiO}_{2}$ particles impregnated upto a few microns depth of AC, d) EDAX spectra of highlighted portion, ${ }^{49)}$ e) Nanowires coating on the calcium aluminasilicate beads (author's unpublished work).

organic layer also suppressed the aggregation of nanoparticles in the solution. Using such in-situ surface modification the particles' surfaces can be changed to hydrophilic or hydrophobic and also the surface energy can be altered, which are the key factors in the biomedical applications.

The doping and impregnation of titania particles with some active elements or molecules, the combination of titania with some supports like molybdenum, zeolites, $\mathrm{CNT}, \mathrm{ZrO}_{2}$, hydroxyapatite, etc. and the coating of titania nanoparticulates on the calcium alumina-silicate beads, and coating of titania surfaces with $\mathrm{Pt}, \mathrm{Ag}, \mathrm{Au}$, rare earth oxides, polymers, etc., produce unique hybrid materials with special properties (Fig. 9). The present author has obtained fine nanowires coating on the calcium alu- 
mina-silicate beads as supports (Fig. 9(c)). There are several reports related to this aspect. ${ }^{45)-49)}$ These reports also support the fact that such hybrid nanomaterials have better performance in the catalytic applications.

\subsubsection{Zinc oxide}

It is a wide band gap semiconductor and a promising material for UV light emitting and lasing devices because of its large exciton-binding energy. ${ }^{50)}$ The other applications of $\mathrm{ZnO}$ are as varistor, gas sensor, transducer, catalyst, phosphor for bio-imaging, etc. Among all the preparative methods for $\mathrm{ZnO}$ synthesis, the supercritical hydrothermal method has a special feature for the continuous and rapid production in the form of fine nanostructures with a varying morphologies like nano-rods, nano-belts, nano-cages, nano-combs, nano-wires, nano-springs, nano-sprials and nano-rings. There are several reports on the synthesis of $\mathrm{ZnO}$ nanoparticles both under sub-critical and supercritical hydrothermal conditions $\left(T=200\right.$ to $\left.400^{\circ} \mathrm{C}\right)$. The metal ion dopants like $\mathrm{Sb}, \mathrm{Bi}, \mathrm{In}$, and Mo have been used in order to obtain different morphologies like plates, prisms, rods and needles with different aspect ratios for $\mathrm{ZnO}$ crystals. Here, the metal ions have been used in very small quantities (initial concentrations from 8 to 30 mmol with respect to $\mathrm{Zn}$ in $\mathrm{ZnO}$ ) and significant effect on the morphology of $\mathrm{ZnO}$ crystals was noticed. Since the experiments were carried out at mild conditions (temperature at $150^{\circ} \mathrm{C}$ and pressure less than 10 bars), it is predicted that the molecular dynamic forces are weak and the growth rate is also not very high, and hence the diffusion is highly controlled, such that the crystal quality is generally high with minimum possible lattice defects. Also because of the moderate crystal growth rates the crystals are usually facetted inspite of very small size (Fig. 10). Dopants do modify the morphology of the $\mathrm{ZnO}$ crystal such that the growth along 0001 axis becomes prevalent when $\mathrm{Sb}$ or Mo (Fig. 10) is used. On the other hand, doping of In into $\mathrm{ZnO}$ crystals at high pressure and temperature around $100 \mathrm{MPa}$ and $400^{\circ} \mathrm{C}$ strongly reduces the growth along 0001 axis. ${ }^{51)} \mathrm{A}$ wide range of surfactants like hexanol, hexanal and hexylamine have been used under supercritical conditions to modify the surface charges. When hexylamine was used as a surfactant, it puts the alkyl groups on the outer surface and the surface becomes hydrophobic. The nanoparticles formation reactions are given below ${ }^{52)}$ :

$$
\begin{aligned}
& \mathrm{Zn}\left(\mathrm{NO}_{3}\right)_{2}+2 \mathrm{H}_{2} \mathrm{O}=\mathrm{Zn}(\mathrm{OH})_{2}+2 \mathrm{HNO}_{3} \\
& \mathrm{Zn}(\mathrm{OH})_{2}=\mathrm{ZnO}+\mathrm{H}_{2} \mathrm{O}
\end{aligned}
$$

The first step is the hydrolysis of a metal salt to produce metal hydrous oxide, and the second step is dehydration of the hydrous oxide to produce metal oxide. The surface modified nanorods are well dispersed in the water/chloroform binary system, whereas the non-modified $\mathrm{ZnO}$ rods do not show the same level of dispersion as the modified ones. Hence, the surface modification can be an effective tool to obtain highly advanced nanoparticles without the problems of coagulation under supercritical hydrothermal conditions. The analytical tools like FTIR spectroscopy and TGA can provide valuable information on the existence and elimination of these surface modifiers at the surface of the products.

It is interesting to note that in most cases, the surfaces of the oxide particles formed in hydrothermal conditions were terminated by hydroxyl or ether groups. Therefore, the oxide particles were hydrophilic and well dispersed into water and other solvents whose dielectric constant is high. The one possible way to modify the surface of the oxide particles is to use reagents that react with the hydroxyl group. The reader can get more informa-
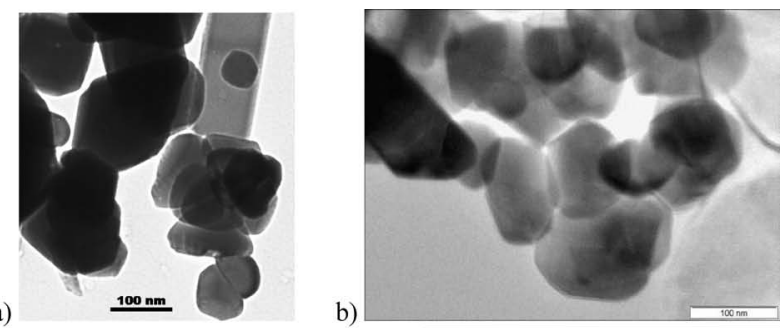

a)
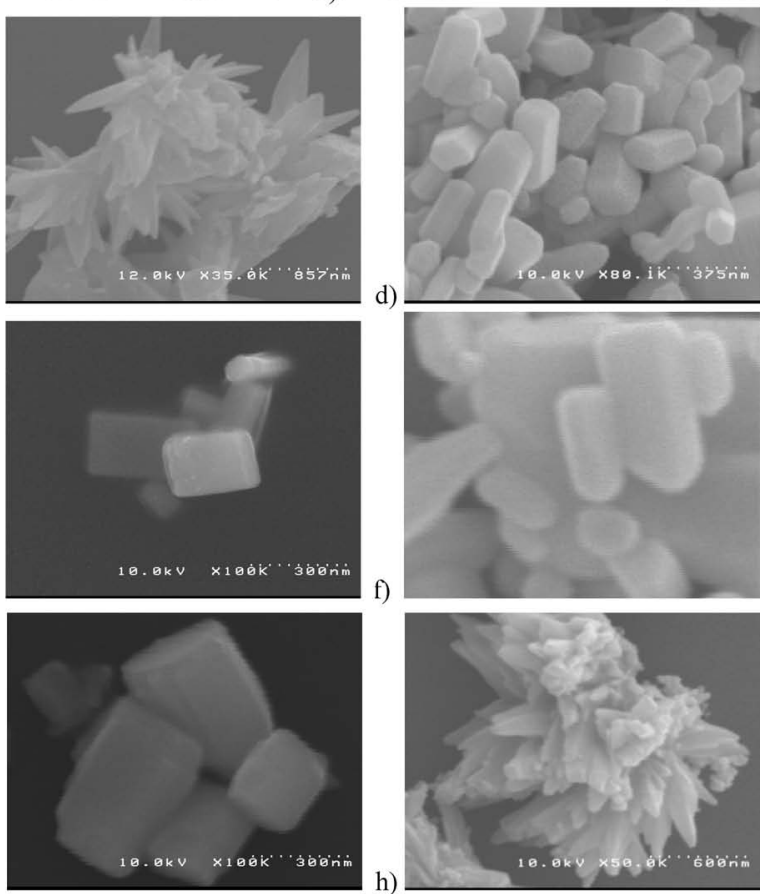

Fig. 10. $\mathrm{ZnO}$ crystals obtained under hydrothermal conditions: a) undoped, b) Sb, Li codoped, c) tungsten doped, d) indium doped, e) silver doped, f) neodymium doped, g) chromium doped, h) molybdenum doped (from the works of Prof.K. Byrappa).
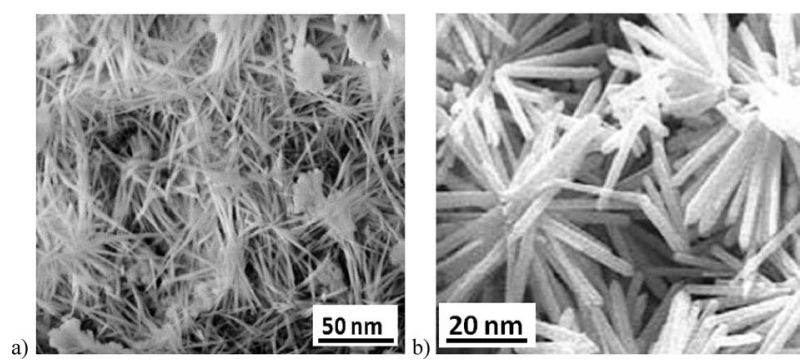

Fig. 11. ZnO coating on calcium alumina-silicate beads under hydrothermal conditions (unpublished work of K. Byrappa).

tion on the surfactants in supercritical fluids in the works. ${ }^{53), 54)}$

There are several reports on the preparation of $\mathrm{ZnO}$ based nanocomposites like impregnation of $\mathrm{ZnO}$ onto activated carbon, template growth of $\mathrm{ZnO}$ on $\mathrm{Al}_{2} \mathrm{O}_{3}, \mathrm{ZnO}$ on carbon nanotubes, ${ }^{55)}$ $\mathrm{ZnO}$ coating on the calcium alumina-silicate beads as support under hydrothermal conditions. ${ }^{56)}$ Figure 11 shows $\mathrm{ZnO}$ coating on the calcium alumina-silicate beads.

The photocatalytic activity of the metal oxide nanoparticles is being studied extensively by researchers. The investigations carried out by the author's group observed that in case of rare earth vanadates, the photodegradation efficiency is around $80 \%$ and 
the COD estimated amount is around 88 . These values depend greatly on the size of the nanoparticles, and also the several other parameters such as surface charge, doping, the light intensity, exposure time, quantity of the catalyst in the system, etc. Similar results have been obtained for titania and zinc oxide, especially for the zinc oxide particles coated on the calcium aluminosilicate beads, which show around $95 \%$ photocatalytic efficiency and the percent transmission raises up to $97 \%$. These values present higher application potential for these nanocomposite materials processed using hydrothermal solution method under mild conditions.

\section{Conclusions}

The hydrothermal solution processing of materials on the whole has undergone a myriad evolution since its inception as a tool to process technological materials in the sense; the PT conditions of processing are now inclined towards the green technology. The wasteless processing is the future of materials processing with an eye on the environmentally benign conditions without leading to the global warming. An understanding of the thermodynamic calculations has contributed to the intelligent engineering of the materials with the desired shape, size and also physic-chemical properties. Similarly, the use of multi-energy processing leads us to a new concept in science, viz. Chemistry at the speed of light. The combination of hydrothermal technology and nanotechnology can answer most of the problems associated with advanced materials processing in 21 st century. The addition of surfactants and chelates in the hydrothermal system changes the surface chemistry of nanomaterials making them either hydrophilic or hydrophobic, and gives the desired shape and size to the particles. These are the stringent requirements in the biomedical applications of the nanomaterials. This has resulted in the new preparative chemistry of materials processing. The hydrothermal solution processing has been proved to be highly effective in the synthesis of advanced nanomaterials like carbon polymorphs, rare earth vanadates, titania and zinc oxides. The hydrothermal coating of titania and zinc oxide as fine nanocrystals, nanowires and films on the calcium alumina-silicate beads has produced novel nanocomposite mateirals with greater application potential, especially as photocatalysts than the pure metal oxides. The photocatalytic properties depend upon the particle size, percent of dopant concentration, light intensity, exposure time, etc. The use of such advanced materials in the present work has shown about $95 \%$ photocatalytic efficiency with the percent transmission touching $97 \%$.

Acknowledgements The author wishes to thank Prof.M. Yoshimura, Professor Emeritus, Materials Structures Laboratory, Tokyo Institute of Technology, Nagatsuta Campus, Yokohama, Japan; Prof.T. Adschiri, IMRAM, Tohoku University, Katahira Campus, Sendai, Japan; Prof.B. Basavalingu, DOS in Geology, University of Mysore, Mysore, India; and the research students Dr.A.K. Subramani, Mr.P. Madhusudan, Mr.C.K. Chandrashekar, Mr.C.P. Sajan, and Mr.H.P. Shivaraju for their help in preparing this review.

\section{References}

1) K. Byrappa (Ed.), "Hydrothermal Growth of Crystals, Prog. Cryst.," Grow Charact. 21 (1990).

2) K. Byrappa and M. Yoshimura, "Handbook of Hydrothermal Technology," Noyes Publ., N. J., USA (2001).

3) K. Byrappa, Hydrothermal Processing of Advanced Materials, In: "Kirk-Othmer Encyclopedia of Chemical Technology," John Wiley \& Sons, London (2005).
4) L.W. Jelinski, T. E. Graedal, R. A. Laudise, D. W. McCall and C. K. N. Patel, Proc. Natl. Acad. Sci., 89, 793-798 (1992).

5) M. M. Lencka, A. Andreko and R. E. Riman, J. Am. Ceram. Soc., 78, 2609-2614 (1995).

6) Y. Hao and A. S. Teja, J. Mat. Res., 18, 415-420 (2003).

7) R. E. Riman, W. L. Suchanek, K. Byrappa, C. W. Chen, P. Shuk and C. S. Oakes, Solid State Ionics, 151, 393-398 (2002).

8) M. Yoshimura and K. Byrappa, J. Mat. Sci., 43, 2085-2103 (2008).

9) K. Byrappa and T. Adschiri, Prog. Cryst. Grow. Charact. Mat., 53, 117-166 (2007).

10) M. Faraday, Philos. Trans. R. Soc. London, 147, 145-148 (1857).

11) M. Yoshimura, S. E. Yoo, M. Hayashi and N. Ishizawa, Jpn. J. Appl. Phys., 28, L2007 (1989).

12) K. V. Chroustshoff, Ann. Chemist., 3, 281-288 (1873).

13) G. W. Morey, J. Am. Ceram. Soc., 36, 279-285 (1953).

14) J. B. Hannay, Proc. Royal Soc. London, 30, 178-181 (1880).

15) G. Spezia, Atti. Accad. Sci. Torino, 35, 95-99 (1900).

16) M. Yoshimura, W. L. Suchanek and K. Byrappa, MRS Bull. $25,17-25$ (2000).

17) J. Jung and M. Perrut, J. Supercritical Fluids, 20, 179-219 (2001).

18) K. Byrappa, S. Ohara and T. Adschiri, Adv. Drug Deliv. Rev., 60, 299-327 (2008).

19) K. Sue, Y. Hakuta, R. L. Smith Jr, T. Adschiri and K. Arai, J. Chem. Eng. Data, 44, 1422-1999 (1999).

20) S. Ohara, T. Mousavand, T. Sasaki, M. Umetsu, T. Naka and T. Adschiri, Continuous production of fine zinc oxide nanorods by hydrothermal synthesis in supercritical water, $J$. Mater. Sci., 43 (2008).

21) T. Mousavand, Ph. D., Thesis, Tohoku University, Sendai, Japan (2007).

22) T. Adschiri and K. Byrappa, "Nano-hybridization of OrganicInorganic Materials," Ed. by A. Muramatsu, Springer-Verlag, Germany (2008).

23) M. Schrauder and O. Navon, Nature, 365, 42-44 (1999).

24) O. Navon, Nature, 353, 746-749 (1991).

25) S. Heggerty, Nature, 320, 34-36 (1986).

26) G. D. J. Guthrie, D. R. Veblen, O. Navon and G. R. Rossman, Earth Planet Sci. Lett., 105, 1-5 (1991).

27) R. C. DeVries and S. Sōmiya, Ed., "Advanced Ceramics," Vol. III, Elsevier, Amsterdam (1990) pp. 181-189.

28) R. C. DeVries, R. Roy, S. Sōmiya and S. Yamada, Trans. Mater. Res. Soc. Jpn., 14B, 641-649 (1994).

29) V. G. Vasil'ev, V. P. Koval'ski and N. V. Cherski, Origin of Diamond, Nedra, Moscow, Russia (1968) [in Russian].

30) Yu. L. Orlov, "Mineralogy of Diamond," Nauka, Moscow (1973) [in Russian].

31) C. A. Eckert, B. L. Knutsan and P. G. Debenedetti, Nature, 383, 313-316 (1996).

32) B. Basavalingu, J. M. Calderon Moreno, K. Byrappa and Y. G. Gogotsi, Carbon, 39, 1763-1765 (2001).

33) B. Basavalingu, K. Byrappa, P. Madhusudan, A. S. Dayananda and M. Yoshimura, J. Mater. Sci., 41, 1465-1468 (2006).

34) B. Basavalingu, P. Madhusudan, A. S. Dayananda, K. Lal, K. Byrappa and M. Yoshimura, J. Mater. Sci., 43, 2153-2157 (2008).

35) M. Yu, J. Lin, Z. Wang, J. Fu, S. Wang, H. J. Zhang and Y. C. Han, Chem. Mater., 14, 2224-2231 (2002).

36) K. Byrappa, K. M. L. Rai, B. Nirmala and M. Yoshimura, Mater. Sci. Forum, 315-317, 506-513 (1999).

37) K. Byrappa, Ramaningaiah, C. K. Chandrashekar, K. M. Lokanatharai, B. Basavalingu and K. Soga, J. Mater. Sci., 41, 1415-1421 (2006).

38) K. Byrappa, C. K. Chandrashekar, B. Basavalingu, K. M. LokanathaRai, S. Ananda and M. Yoshimura, J. Cryst. Growth, 306, 94-101 (2007). 
39) A. Fujishima and K. Honda, Nature, 238, 37-38 (1972).

40) R. Wang, K. Hashimoto and A. Fujishima, Nature, 388, 431-432 (1997).

41) B. O'Regan and M. Gratzel, Nature, 353, 737-740 (1991).

42) T. Saito, T. Iwase, J. Horie and T. Morioka, J. Photochem. Photobiol., B Biol., 14, 369-379 (1992).

43) H. Hayashi and K. Torii, J. Mater. Chem., 12, 3671-3676 (2002).

44) T. Mousavand, J. Zhang, S. Ohara, M. Umetsu, T. Naka and T. Adschiri, J. Nanoparticle Research, 6, 9186-9190 (2007).

45) K. Byrappa, D. Rangappa, K. M. L. Rai and M. Yoshimura, Trans. Mater. Res. Soc. Japan, 29, 2407-2411 (2004).

46) K. Byrappa, M. H. Sunitha, A. K. Subramani, S. Ananda, K. M. L. Rai, B. Basavalingu and M. Yoshimura, J. Mater. Sci., 41, 1369-1375 (2006).

47) A. K. Subramani, K. Byrappa, G. N. Kumaraswamy, H. B. Ravishankar, C. Ranganathaiah, K. M. L. Rai, S. Ananda and M. Yoshimura, Mater. Lett., 61, 4828-4831 (2007).

48) C. P. Sajan, H. P. Shivaraju, K. M. L. Rai, S. Ananda, M. B. Shayan, T. Thonthai, G. V. N. Rao and K. Byrappa, Mater. Res. Innov., (in print).
49) H. P. Shivaraju, C. P. Sajan, T. Rungnapa, M. S. V. Kumar, C. Ranganathaiah and K. Byrappa, Mater. Res. Innov (in print).

50) M. H. Xuang, S. Mao, H. Feick, Y. Yan, Y. Wu, H. Kind, E. Weber, R. Russo and P. Yang, Science, 292 (8 June), 1897-1899 (2001).

51) D. Ehrentraut, M. Miyamoto, H. Sato, J. Riegler, K. Byrappa, K. Fujii, T. Fukuda and T. Adschiri, Cryst. Growth Des., 8, 2814-2820 (2008).

52) T. Adschiri, Y. Hakuta, K. Sue and K. Arai, J. Nanoparticle Res., 3, 227-231 (2001).

53) J. L. Panja and E. J. Beckman, "Supercritical Fluid Technology in Materials Science and Engineering," Ed. Y.-P. Sun, Marcel Dekker Inc., New York (2002) pp. 255-284.

54) H. M. Woods, M. M. C. G. Silva, C. Nouvel, K. M. Shakesheff and S. M. Howdle, J. Mater. Chem., 14, 1663-1678 (2004).

55) K. Byrappa, A. K. Subramani, S. Ananda, K. M. L. Rai, M. H. Sunitha, B. Basavalingu and K. Soga, J. Mater. Sci., 41, 1355-1362 (2006).

56) H. P. Shivaraju, K. Byrappa, M. B. Shayan, T. Rungnapa, S. Pakamard, M. S. V. Kumar and S. Ananda, Mater. Res. Innov., (in press).

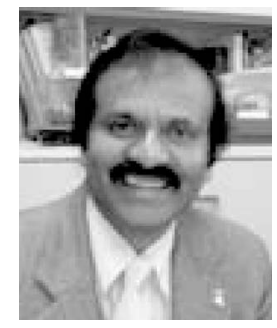

Prof. K. Byrappa received his B.Sc and M.Sc degrees with ranks and gold medals from the University of Mysore. Later he obtained his Ph.D degree and Post Doctoral training from Moscow State University, Russia. After joining the University of Mysore, he worked extensively on the Crystal Growth and Materials Processing for various applications including the environmental issues, using the Hydrothermal Technique. He has a well established laboratory for hydrothermal research, which is well recognized in the world. Prof. Byrappa has international collaboration with several well known laboratories. He has received many awards both within and outside India. To mention a few: Sir C.V. Raman Award in 1998; Attractive Paper Award in the IX International Conference on Crystal Growth, Sendai, Japan, August 1989; Golden Jubilee Award of the University of Mysore for the best research work twice in 1987 and 1992; Materials Research Society of India Medal in 2005. Prof. Byrappa has published 176 research papers and reviews in international journals. Currently he is very active in the advanced materials processing including Nanomaterials using novel solution routes like Hydrothermal, Solvothermal and Supercritical techniques. Prof. Byrappa has authored and edited TEN books from famous international publishers. Prof. Byrappa has written chapters on Hydrothermal Technology for several Encyclopaedias and Handbooks. He is the Associate Editor of several international journals, and to name a few: Progress in Crystal Growth and Characterization of Materials, published by Elsevier Publishers, Oxford, UK; Materials Research Innovations, from Maney Publications, UK, Guest Editor of Journal of Materials Science, published from Springer, USA. He is serving as an Executive Council member of several international bodies and commissions like: International Commission on Crystal Growth and Characterization, International Commission on Mineral Synthesis, Asian Crystallographic Association, National Crystallographic Association, INSA National Committee on Crystallography, working as the First General Secretary of International Solvothermal and Hydrothermal Association (ISHA), etc. He has widely travelled and worked in several international laboratories in the world. Prof. K. Byrappa has organized several International symposia abroad, and also has delivered a large number of Plenary, Keynote and Invited Talks in various International Conferences held in various countries all over the world. 